\title{
A Brief Literature Review on Acculturation Strategies of Overseas Students
}

\author{
Kefeng $\mathrm{Fu}^{1}$ \\ ${ }^{1}$ College of Humanities and Foreign Languages, Xi' an University of Science and Technology, China \\ Correspondence: Kefeng Fu, College of Humanities and Foreign Languages, Xi'an University of Science and \\ Technology, Lintong District, 710600, Xi'an city, Shaanxi Province, China. Tel: 86-135-714-921-26. E-mail: \\ fkf2001@126.com
}

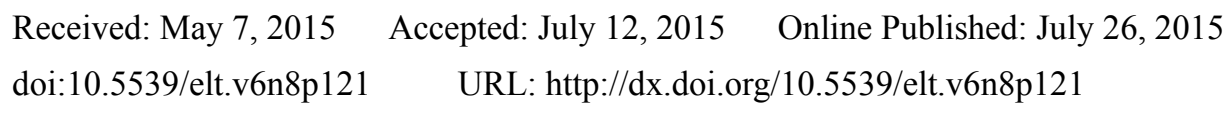

\begin{abstract}
Acculturation strategy has been an integral and essential part in the field of acculturation study. The fact that an increasing number of international overseas students wave into China renders this research urgently in need; and new theoretical models emerged constantly, which have had a significant effect on the immigration policies in China. This paper, based on the exemplification of the significance of acculturation study, aims to display the setting, clarify such three frequently confusing terms as adaptation, acculturation, adjustment by comparing and contrasting the similarities and differences before fixing the acculturation as this study's preference, then presents a brief but clear description of the history, dimensions, and subjects of acculturation study, and finally discuss two kinds of acculturation modes, four acculturation strategies in particular held by John Berry: assimilation, separation, integration, and marginalization.
\end{abstract}

Keywords: acculturation strategies, integration, separation, assimilation, marginalization

\section{Introduction}

No study is conducted in a vacuum and it must be connected with the past and future. A literature review offers such contextual information, which not only describes what has already been done in the field and what problems remain to be unsolved, but also explains to what scale one's study is distinguishable from the previous ones, what kind of contribution can be made to the existing knowledge, how the design of one's design is based on if there is any (Wen, 2001). That's why the this study starts with the some relevant literature review only to find that there are few of scholars who pay attention to this issue, and that the choice of acculturation strategy arouse little attention of the domestic scholars. Virtually, Contact between culturally diverse individuals is as old as preserved history. Individual fostered in one culture have always visited other communities to business with, learn from, or exert impacts on foreign lands. Most communities have witnessed visitors from abroad, being hospitable to them on condition that their motives were seen to be benevolent, or unfriendly to the newcomers if they came to invade, pillage or even conquer. The journals of Xenophon, Marco Polo, Columbus, Drake, Captain Cook, Burton, and Lafcadio Hearn offers superb accounts of what nowadays we would call intercultural contact, during the process of which they also touch on some of the interpersonal and sociopolitical difficulties. The difference between then and now lies in merely the scope where the quantum increase in the movement of people across national and ethnic boundaries due to factors including mass access to jet travel, globalization of industry, expansion of educational exchanges, growing migrants, refugees, and foreign worker movements. And among all these sojourners, overseas students experienced relatively more unfamiliarity and confusions, and thereby accumulated more strategies to cope with those unexpected occurrence due to their long sojourn in a foreign culture (Hu, 2000).

\section{Significance of This Research}

To have a relatively high academic study of the so-called acculturation issue, acculturation strategies in particular, gain a practical and theoretical significance. This research prefers to elaborate the significance of this study from the following two aspects. On the one hand, the fact that an increasing number of international overseas students wave into China renders this research urgently in need. In 1950, China began to enroll the first group of overseas students to be educated, exactly speaking, only five Romanian students. Till now, 65 years have already passed during which China has raised large quantities of science and technology, education, diplomacy talent for various 
countries, especially those developing ones. With the reform and open policy moving on, China's comprehensive national strength gradually increased, the international standing unceasingly enhanced, and the international education program has made great progress. The dimension and structure of the international education program are also changing from language-purposed student to undergraduate student, and graduate student. According to Foreign Affairs Office in China, the number of Chinese overseas will increase to 220,000 at the end of 2015. Obviously, China is becoming a "Holy land" for those who want to study abroad. At the same time, the increased number of international students flooding into China brings about a great challenge for the Chinese educational system and management pattern. Chinese universities and colleges are responsible for offering different kinds of services for the overseas students and solving the problems experienced by them mentally and physically. It is assumed that intercultural contact not only brings about excitement and mystery, but also stress and depression, which is a process full of wonder and unfamiliarity. As student sojourners they experienced a range of difficulties, such as inadequate linguistic and communicative strategies, racial bias or discriminations, homesickness and loneliness. They also face pressures associated with the role of 'foreign ambassador' in their interactions with host culture students (Collen et al., 2001). Without adequate supplement and assistance, those problems must become worse, and even contributes to a tragedy. What's worse, the negative acculturation situation in host country directly affects the overseas' judgment upon the host country and threaten the image of host country in the world. This issue, unfortunately, has not aroused attention of the domestic scholars and researchers in China, Thus, this research is urgently in need. On the other hand, at the background of specific Chinese and cultural system, this study, adding freshness, fullness and vigor to the existing study of acculturation, in particular, acculturation strategy, may demonstrate a new and diverse angle for the further study of acculturation theory. After a synchronic and diachronic analysis of the existing literature in this field, the author staggeringly notices that most of the researchers in this field more often prefer to Westernize, or particularly Americanize their academic research. That is to say, those researchers tend to apply their western or American social background in their cases. P.G.Altbach, one of the remarkable experts in the field of International Education Comparison, founder of Pull-Push theory in Boston College, once pointed that, "the existing literature in this field mainly focuses on various problems of overseas from developing countries experienced in industrial or developed countries. Although those issues are the mostly concerned and heatedly argued, they are still a part of whole (Yang, 2005)." Here, it is not necessarily cogent to apply those literature or findings by westerners to explain and clarify the problems experienced in some developing countries, such as China. Concerning the establishment of acculturation theory, those researches or scholars from western countries have already built up a relatively solid concept system of paradigm. In other words, a westernized or Americanized discourse, which overwhelmed the field of politics, economics, and social culture in this global village for a long time, has emerged and worked (Kim, 1986). Of course, it is not to say that this mature system of western discourse should be abolished or even replaced. In fact, these are the contribution of hundreds of thousands former scholars and experts' knowledge and wisdom. It is not wise to give it away. However, the trouble is that these developing countries, without critically thinking, would merely apply this western-orientation system to explain their own specific problems, a large quantity of genuine and dynamic localization resource would be probably left in the dust largely owing to being disagreement with the so-called mainstream discourse hold by western society. From this point of view, this author argues that it is urgently desirable to change the western-orientation discourse or paradigm to a more diverse and dynamic one, or at least establish a combinational one of western-orientation and east-orientation. But we have to admit that it is a great challenge to be coexistent with the western one.

\section{Defining the Three Terms: Adaptation, Acculturation, and Adjustment}

As a critical concept of intercultural communication, acculturation needs further study in spite of the abundant researches since 1990s. One of the suggestions from Kim (1986) and Swarl and ward (1880) for further research in this field is that the terms used to describe sojourners' experience in a new culture are vague; those terms commonly used, including acculturation, adaptation, adjustment, assimilation, integration, resocialisation, transculturation, and transformation, needs to be conceptually defined (Chen, 2001). Inspired by this idea and expecting to hunt for sound theoretical support, the author takes a look at the definition to three frequently used terms: adaptation, acculturation and adjustment.

Intercultural adaptation is commonly applied in the literature of intercultural communication studies, and according to Kim, "it refers to the process of increasing the level of fitness of people to meet the demands of a new cultural environment, and it deals with how sojourners or new immigrants experience the distress caused by mismatches or incompatibility between the host culture and the culture of birth (Kim, 1998)." And Kim further develops this idea when she writes, "Cross-Cultural adaptation embraces other similar but narrow terms, from assimilation... and acculturation ...to coping and adjustment... as well as integration (Kim, 1986)." And in her 
article Cross-cultural adaptation: An Integrative Theory(Kim,1995), she defines acculturation as the process of learning the elements of the host culture to be a member of it, and discusses it together with deculturation, which is then defined as one's old cultural habits. This acculturation-deculturation process forms one of the three "open-systems" assumptions of Kim's integrative theory of intercultural adaptation. Likewise, in Mansell's Dimension of intercultural adaptation, acculturation is considered as one of the four emotional and affective states, besides alienation, marginality, and duality, in the process of intercultural adaptation. In this state, sojourners establish a strong need to adapt the way of living of the host culture, and they are able to make intimate friends with the host nation and are able to replace some elements of their original culture with elements of the host culture, a group of scholars represented by Kim and Mansell reach the agreement and abandon their own culture.

However, a disagreement can be observed from Kim's own works, from mid 1980s, she has been composing a sequence of well-known articles by using the concept of acculturation instead of adaptation, like Acculturation Attitude of Korean Immigrants in Toronto, Comparative Studies of Acculturation Stress. In these articles Kim adopts the definition of acculturation by Redfield Linton, and Herskovits, who coin acculturation as a process of adaptation to strange surroundings largely due to two independent cultures encountering with each other. Relatively speaking, both of them perceive acculturation from a much broader perspective, not just as the state of wholly adopting the host culture on the one hand. The first users of this term are mainly psychologists, they thus tend to give more emphasis on its psychological side.

Instead of embracing "adjustment" under the meaning of "adaptation", Furnham and Brochner put them on an equal footing. In the article "Social Difficulty in a Foreign Culture: An empirical Analysis of culture Shock" published in 1982, they explore out the nature and extent of the social difficulties sojourners encounter in the intercultural adjustment, and offers their famous framework in the process of intercultural adjustment study by analyzing three factors: cultural difference, individual difference, and sojourner experience. Still, some other scholars put "adjustment" in a rather narrow sense, among them, Lysgaard, the founder of the famous U-Curve theory, is a good representative. Here adjustment is defined as the third stage of intercultural adaptation, after honeymoon and crisis, and before biculturalism. It refers to the very period in which sojourners begin to appreciate and respect the new culture and to develop sensibility towards cultural differences. Studies from the new Chang (1973) and Morris (1960) confirmed the U-Curve Theory and adopted the narrow sense of adjustment.

By reviewing the relevant literature, this study prefers the term acculturation. First, adaptation is used by scholars in a broader sense, but intercultural adaptation and acculturation are often cross-referenced. Secondly, acculturation, instead of adaptation and adjustment, represents the most current thinking in the field. Last but not least, the theoretical framework, acculturation strategies, which this current study is based on and which will be illustrated later.

\section{The Chronological Development, the Subject and Dimension of the Acculturation Study}

The notion of acculturation is derived from anthropology, which has been followed by other disciplines such as sociology, epidemiology, and inter-cultural psychology. However, the theoretical and applied findings in terms of these disciplines have been endowed with various approaches and applications. When anthropologist Redfield and others recognized acculturation as an object of study in 1936, they termed it broadly as "those phenomena which result when groups of individuals having different cultures come into continuous first-hand contact, with subsequent changes in the original cultural patterns of either of both groups" (Redfield, Linton, \& Herskovits, 1936).

\subsection{The Burgeoning Period}

The earliest work relating to acculturation study arose in the context of research on migration and mental health. Its origins were perhaps more sociopolitical than psychological and can be traced back to the use of early twentieth century census records in the United States. Statistics based on data collected in 1903 from state mental institution indicated that immigrants constituted 70 percent of hospitalized patients despite representing only 20 percent of population at large (Portes \& Rumbaut, 1990). These findings had significant social, economic and political consequences at the time and were subsequently used to support the establishment ofimmigration screening programs in United States (Furnham \& Bochner, 1986). Later, more sophisticated epidemiological investigation in the United States also suggests that migrants were over-represented in hospital admissions (Lysgaard,1932). This stimulates an increase in systematic comparative studies of immigrants and native-born, a line of research that continued for more than three decades and expanded to the international area, investigation in United Kingdom, Australia, Canada, Germany and South Africa consistently supported the association 
between migration and psychiatric morbidity.

\subsection{The Developmental Period}

As research on migration and mental health progressed into the $1980 \mathrm{~s}$, a number of investigators began to question the uniformly high reported incidence of psychiatric morbidity in immigrants. Indeed, studies began to emerge that documented lower rates of institutionalization in selected migrant samples (e.g. Cochrane, 1977; Wong \& Cochrane, 1989). At the same time researchers began to shift their data bases from archival records on hospitalization and the diagnosis of psychotic disorders to community surveys of psychological distress, including anxiety, depression, and psychosomatic complaints. In this period, the problem with studies of this era, however, was that many of them were atheoretical and used what Brisling and Baumgartner (1971) have called 'samples of convenience' rather than properly constituted representative groups of participants. The preferred methodology was to administer a questionnaire that included a variety of items about the respondents' adjustment problems and attitudes to the host country.

\subsection{The Golden Period}

Since the mid of last century, the volume of empirical study on intercultural acculturation has significantly increased. Studies of this field have proliferated over the last two decades. It stepped into its golden developmental phase. In this period, the methodology has been improved and refined; the scope of the study has been extended ranging from immigrants, overseas, and patriots to sojourners, experts, and businessman. In contrast to the former studies, which tend to take the immigrants and foreign sojourners as a whole, and focus on the group acculturation to social structure and their change ethnic or cultural identity, in this period researchers, such as psychologists, andlinguists, they have focus on quantification through psychometrical scales and on description of individual-level changes with acculturation. According to Berry's representative model of acculturation stress, for instance, an individual's early mental responses to the conflict often along with acculturation may result in diminished mental health status, which later improves acculturation.

\subsection{The Subject and Dimension of the Acculturation Study}

There are, at least, two ways in which the process of intercultural acculturation can be described, corresponding to different approaches and emphases in the multidisciplinary literature. One may be summarized as the research subject, exactly speaking, which can be both short-term and long-term exposure to host culture. The other may be categorized from both micro or individual and macro or group level.

As for the subject of acculturation research could be classified as two sorts. One is long-term exposure to host culture, such as immigrants and refugees, whose acculturation is a life-time experience. The other could be generally addressed as sojourners who are so-called short-term or instant exposure to host culture. A sojourn is defined as a temporary stay in a new place. It occurs voluntarily for an unspecified, though relatively short, period of time. Although there are no fixed criteria for defining a sojourn in terms of its duration, 6 months to 5 years are commonly cited parameters. There are many types of sojourners: expatriate business people, diplomats, members of the armed forces, students, volunteers, aid workers, and missionary. They do business; represent their country; protect civilians or proselytize respectively. Although there have been some studies of expatriate business people, diplomats, members of the armed forces, aid workers, and missionary, most sojourn research has concentrated on international students. The literature on international students has, to some extent, reflected the need to sustain the education export industry, and a significant portion of the contemporary literature has dealt with the problems of international students, however, as international students sojourners are perhaps the best-researched group of cross-cultural travelers, there is extensive body of work that has focused on theory testing.

As for the dimension of acculturation study, it could be sorted as individual and group level. In the past, acculturation study mainly focused on the issue from the perspective of anthropology and sociology in order to draw the distinction of different cultures, which thus tend to investigate the cultural variation caused by cultural contact based on the group level. While in contrast to the sociological emphasis on economic, political and social structure, efforts in individual acculturation have focused on quantification through psychometric scales and on description of individual-level changes with acculturation. In Berry's well-known model of acculturation stress, for instance, an individual's first psychological echo to these disagreements which often emerge are likely to contribute to decreased mental health, which, instead, later promotes acculturation.

\section{Acculturation Models}

\subsection{Unidirectional Model of Acculturation}

Acculturation is firstly regarded as a direct unidirectional notion that supposes the acculturating subject will 
follow the rules and notions of the target culture. To say, the "melting pot" approach supposes that optimal acculturation procedure for the subject is to adapt to the target culture. Suppose individuals fail to assimilate, accordingly, they will suffer from tremendous loneliness, anxiety, as well as tension. Virtually, various experts concerning this field hold distinctive stands in terms of evaluating individual's acculturation level. Mendoza, the outstanding scholar in this field, points that some models are apt to apply a single index or standard, for example, the issues scaling merely the individual's proficiency or capability of four linguistic skills in target language, when evaluating the acculturating subjects' benchmark of accommodation to the target culture, who, whereas, also asserts that several unidirectional patterns have utilized multidimensional measures. Multidimensional measures consist of issues concerning the subjects' capacity to be involved in the target culture, to list, food culture, custom, and dressing style.

The unidirectional model further assumes that the more complex the society is, the more it is uni-polar, and assimilated. The reliability of this assumption has not only been challenged, but doubted, for example, in the United States, Glazer and Moynihan initially supposes that minorities will homogenize into the American mainstream stream and finally fade; they also conclude, however, minorities have not only survived, but also there is a sharp rise with ethnicity much more salient than ever before, this disadvantage has give rise to alternative opinion in terms of acculturation.

\subsection{Bidirectional Model of Acculturation}

Other scholars have asserted that unidirectional model of acculturation are apt for evaluating the accommodating subjects' own cultural traditions and the cultural effects on their adaptation to the new surroundings. These experts also argued the necessity of the accommodating subject's cultural impacts on the mental condition. For example, it is recommended by Ramirez that it should be probable for the acculturating subjects to make sense and join in proper social occasions or activities within two individual cultures. Respecting that acculturating is a multifaceted of diverse issue; these scholars suggest using a model that would consist of all-rounds channels to evaluate the acculturating individuals' adaptation to the host culture dependant on the impacts of the two cultures It is also indicated that bi-directional models have been applied to probe into the adaptation course of diverse minorities; Berry identifies four kinds of acculturation tactics utilizing a bidirectional approach. Among the Acculturation Attitude Scale, these four tactics are virtually determined. Berry and his peers have addressed diverse issues, to say, verbal communicative ability, religion, customs, child up-bringing and eating habits, in which the acculturating individuals would suggest with a standardized scale ranging from 1 to 5 how strongly they accept or not accept the statement. Berry and his communities have also applied other complementary measures to assess to what degree the acculturating subjects' participation in both the target and their own culture.

With the transformation of acculturation model, the unitary approach of the concept changes as well. The unitary approach of measuring acculturating individual's language proficiency, e.g. speaking, reading and writing, as the only criterion of evaluating their acculturation has gradually yielded to a combined one along with empirical studies and manage to put them into real action. Among them, Berry is a remarkable representative, who established the basic backbone of four acculturation strategies and an array of surveys to measure them.

\subsection{Acculturation Strategies}

According to Berry, there are several stages at the course of acculturation. First, it is common for the acculturation individual to build up a kind of communication with the host culture through commercial business, education, or immigration. Second, from this communication, the individual encounters conflicts due to such difference as food preference, clothing style, and language. Third, to avoid these disagreements, the individual needs to fit in the dominant culture. What's more, Berry also conceptualizes efforts to cope with conflicts and determines four models of acculturation strategies. The transformation of the four acculturation strategies derives from the bidirectional models of acculturation, and is dependent on two dominant issues individuals will be likely to encounter in their everyday life. The first issue is the question whether the individuals are for or against the mother culture's cultural values. The second issue is whether to be for or against target background's concepts and customs. Berry syntheses how great immigrants tend to maintain their traditional culture and the degree to which they long for communications with the host society, a conceptual backbone is built up and the four types of acculturation strategies are determined: integration, assimilation, separation, and marginalization.

The prior strategy, classified as integration, is the one when individuals accept both their own cultural values and those of the host culture. The second one is assimilation. Individuals who apply this strategy refuse their own cultural values and concepts yet accept the host cultural values. The third strategy is separation, which appears when individuals accept their own cultural values and identity and reject those of the host culture. The last 
acculturation strategy is marginalization, which means individuals' rejection to the values and identities of both cultures. Simply speaking, the scale of those four strategies can be summarized in Table 1 .

Table 1. strtegies of acculturation based on the attituedes towards one's own cultutral and towards the host culture

\begin{tabular}{llc}
\hline & \multicolumn{2}{l}{ Attitude towards one's culture } \\
\cline { 2 - 3 } Attitude towards the host culture & Accept & Reject \\
Accept & Integration & Assimilation \\
Reject & Separation & Marginalization \\
\hline
\end{tabular}

Berry and his communities carried out a sequence of empirical studies to evaluate the acculturation strategies of diverse immigrant groups in North America. The results obtained with these immigrants groups display that the strategy of integration is the preferred one if acculturation is followed either by assimilation or separation, while the strategy of marginalization is the least preferred one. Findings have demonstrated that in plural communities, and in relatively mono-polar culture communities, integration is the most adaptive type for immigrants and overseas students, and marginalization is the least one. Similarly, immigrants and sojourners living in the plural societies that follow integration policies are recommended to have better psychological adaptation.

In addition to identifying the favorite acculturation strategy, Berry and his peers have also probed into the relationship among variables such as languages proficiency, nationality, mental stress, and acculturation attitudes of several minorities. To say, Kim and Berry investigated acculturating people that are from the South Korea with good education and are settling down in the big urban areas of Toronto. It is indicated that several factors play a important part in integration, such as enjoying more journals by Canadian, intending to be given questionnaire in English, tripping straightly to Canada, and taking part in various communities in the host country. While, the choice of assimilation displays the different scene: less frequent access Korean journals and TV channels, less friends. In general, those researchers uncover an individual factor of integration as well as assimilation, and most of the subjects got less education as a dominant factor of marginalization and separation. Of course, some other factors are also concerned about the Canadian nationality, more inferior financial rank, too much with the mother identity. One interpretation provided by subjects in a post-interview was urged, whose looking appearance passed for an unique characteristic of Asians, and intend to preserve their original notions and roots. Inspired by their findings, Berry and his communities recommend that with Koreans' literacy increasing, a variety of conflicts, prejudice and hardships will be exposed to them easier, which thereby cornered them to abandon their own original traditions as well customs.

\section{Conclusion}

Based on the relevant literature, it can be easily found that the study of acculturation was even earlier than that of intercultural communication, which witnessed long history and transformation. Virtually, the origin and even development of any promising theory must be linked tightly with the needs of the contemporary society. There is no exception of acculturation study. At the very beginning, the motives of carrying out acculturation study is to explore some effective solutions to tackle the mental problems of the early immigrants, whose findings are thus featured with social, economic and political color at the time and were subsequently used to sponsor the establishment of immigration screening programs in United States As research on migration and mental health move into the $1980 \mathrm{~s}$, an increasing number of investigators or scholars are set out to probe into the uniformly high reported incidence of psychiatric, unfortunately, the problem with studies of this era, instead, was that many of them were at random or casual and used the so-called "sample of convenience" rather than appropriately constructed representative groups of objects. Since the mid of last century, the volume of empirical study on intercultural acculturation has significantly increased. It stepped into its golden developmental phase. In contrast to the former studies, which tend to take the immigrants and foreign sojourners as a whole, and focus on the group adaptation to social structure and their change ethnic or cultural identity, in this period researchers, such as psychologists, and linguists, they have concentrated on quantification through psychometrical scales and on description of individual-level changes with acculturation. As for the subject of acculturation research could be classified as two sorts. One is long-term exposure to host culture, such as immigrants and refugees, whose acculturation is a life-long experience. The other could be generally addressed as sojourners who are so-called short-term or instant exposure to host culture. The dimension could be categorized from both micro or individual 
and macro or group level. In addition, it is also found that the study of acculturation modes become one of the essential issues of acculturation study, which is also the hottest argued issue till now. As a result of various factors, such as divergence, and unclear contents of the scales, the two modes coexist till now. However, generally speaking, the mainstream of acculturation study prefers to adopt bidirectional modes despite some voice of supporters of unidirectional modes. It needs to be pointed that acculturation strategies with four points of a whole continuum sharing somewhat similarities are not stable, but dynamic.

\section{Acknowledgements}

The research is financed by Scientific Research Program Funded by Shaanxi Provincial Education Department (Program No. 12JK0409).

\section{References}

Arthur, N. (2001). Using Critical Incidents to Investigate Cross-Cultural Transition. International Journal of Intercultural Relations, 25, 41-53. http://dx.doi.org/10.1016/S0147-1767(00)00041-9

Berry, J. W., Kim, U., Power, S., Young, M., \& Bujaki, M. (1989). Acculturation Attitudes in Plural Society. Applied Psychology, 38, 185-206. http://dx.doi.org/10.1111/j.1464-0597.1989.tb01208.x

Carrol, D. W. (2000). Psychology of Language. Beijing: Foreign Language Teaching and Research Press.

Chen, G. M. (2001). Foundations of Intercultural Communication. Rhode Island: Thode Island University Press.

Chen, X. (1989). Sojourner and Foreigner: the Study of Cross-culture Interpersonal Communication among Chinese Overseas Students in America. Changsha: Hunan Education Press.

Hu, W. (1999). Panorama of Intercultural Communication. Beijing: Foreign Language Teaching and Research Press. 1999.

Hofstede, G. (1980). Culture's consequences. Beverly Hills, CA: Sage.

Kim, Y. Y. (1986). Cross-cultural adaptation: A Critical Assessment of the Field. Paper presented at the annual meeting of the Speech Communication Association, Chicago, Illinois.

Redfield, R., Linton, R., \& Herskovits, M. (1936). Memorandum on the Study of Acculturation. American Psychology, 38, 1149-1152. http://dx.doi.org/10.1525/aa.1936.38.1.02a00330

Seal, W., \& Ward, C. (1990). The Prediction of Psychological and Sociocultural Adjustment during Cross-cultural Transactions. International Journal of Intercultural Relations, 14, 449-463. http://dx.doi.org/10.1016/0147-1767(90)90030-Z

Yang, J. (2005). Study of Intercultural Adaptation Problems of International Students in China. Wuhan: East China Normal University.

\section{Copyrights}

Copyright for this article is retained by the author(s), with first publication rights granted to the journal.

This is an open-access article distributed under the terms and conditions of the Creative Commons Attribution license (http://creativecommons.org/licenses/by/3.0/). 